Article

\title{
Antiangiogenic and Antioxidant In Vitro Properties of Hydroethanolic Extract from açaí (Euterpe oleracea) Dietary Powder Supplement
}

\author{
Raquel Costa 1,2 $\mathbb{D}$, Daniela Azevedo ${ }^{2,3}$, Pedro Barata ${ }^{1,4}$, Raquel Soares ${ }^{1,2} \mathbb{D}$, Luís F. Guido ${ }^{3} \mathbb{D}$ \\ and Daniel O. Carvalho ${ }^{3, * \mathbb{D}}$
}

1 i3S-Instituto de Investigação e Inovação em Saúde, Universidade do Porto, 4200-135 Porto, Portugal; raquel.costa@i3s.up.pt (R.C.); pbarata@ufp.edu.pt (P.B.); raqsoa@med.up.pt (R.S.)

2 Departamento de Biomedicina, Unidade de Bioquímica, Faculdade de Medicina, Universidade do Porto, 4200-319 Porto, Portugal; up201504492@fc.up.pt

3 REQUIMTE/LAQV, Departamento de Química e Bioquímica, Faculdade de Ciências, Universidade do Porto, Rua do Campo Alegre 687, 4169-007 Porto, Portugal; lfguido@fc.up.pt

4 Faculdade de Ciências da Saúde, Universidade Fernando Pessoa, Praça 9 de Abril 349, 4249-004 Porto, Portugal

* Correspondence: daniel.carvalho@fc.up.pt; Tel.: +351-220-40-26-39

check for

updates

Citation: Costa, R.; Azevedo, D.; Barata, P.; Soares, R.; Guido, L.F.; Carvalho, D.O. Antiangiogenic and Antioxidant In Vitro Properties of Hydroethanolic Extract from açaí (Euterpe oleracea) Dietary Powder Supplement. Molecules 2021, 26, 2011. https://doi.org/10.3390/ molecules 26072011

Academic Editor: Maria Atanassova

Received: 15 March 2021

Accepted: 29 March 2021

Published: 1 April 2021

Publisher's Note: MDPI stays neutral with regard to jurisdictional claims in published maps and institutional affiliations.

Copyright: (c) 2021 by the authors. Licensee MDPI, Basel, Switzerland. This article is an open access article distributed under the terms and conditions of the Creative Commons Attribution (CC BY) license (https:// creativecommons.org/licenses/by/ $4.0 /)$.

\begin{abstract}
The Euterpe oleracea fruit (açaí) is a promising source of polyphenols with health-promoting properties. To our knowledge, few studies have focused on the influence of açaí phytochemicals on angiogenesis, with a significant impact on cancer. This study aimed at investigating the phytochemical profile of a purple açaí hydroethanolic extract (AHE) obtained from a commercial dietary powder supplement by high-performance liquid chromatography coupled to diode array detection and electrospray ionization mass spectrometry, and evaluate its in vitro effects on distinct angiogenic steps during vessel growth and on oxidative markers in human microvascular endothelial cells (HMEC-1). The phenolic profile of AHE revealed the presence of significant levels of anthocyanins, mainly cyanidin-3-O-rutinoside, and other flavonoids with promising health effects. The in vitro studies demonstrated that AHE exerts antiangiogenic activity with no cytotoxic effect. The AHE was able to decrease HMEC-1 migration and invasion potential, as well as to inhibit the formation of capillary-like structures. Additionally, AHE increased antioxidant defenses by upregulating superoxide dismutase and catalase enzymatic activities, accompanied by a reduction in the production of reactive oxygen species. These data bring new insights into the potential application of angiogenic inhibitors present in AHE on the development of novel therapeutic approaches for angiogenesis-dependent diseases.
\end{abstract}

Keywords: Euterpe oleracea; açaí; phenolic compounds; anthocyanins; antioxidants; angiogenesis HPLC-DAD-ESI-MSn

\section{Introduction}

The açaí (Euterpe olerácea Mart.) is a palm tree native to South America and mainly found along the Amazon River estuary, Brazil, Guyana and Venezuela. The açaí fruit, a small and round dark purple berry, gained a great commercial interest in the past years due to its nutritional and functional properties. According to in vitro and in vivo studies, it has been associated with relevant biological activities such as antioxidant and anti-inflammatory properties, as well as anti-carcinogenic, antimicrobial, anti-diabetic, anti-neurodegenerative, and cardio-protective effects [1,2].

Some studies have demonstrated that açaí fruit exhibits antiangiogenic and antiinflammatory behavior responsible for its antitumoral effect $[3,4]$. However, the endothelial mechanisms responsible for the modulation of vessel growth have not yet been elucidated. Angiogenesis consists in the growth of new blood vessels from preexistent vasculature and 
it is one of the key players underlying these processes [5]. Angiogenesis is essential both in physiological conditions, namely during development, tissue repair and reproduction, and in a range of angiogenesis-dependent diseases as cancer, chronic metabolic diseases and cardiovascular diseases. Angiogenic process is a rate-limiting step during tumor growth and metastasis formation, as tumor cells constitute an active source of angiogenic stimuli, as vascular endothelial growth factor (VEGF-A) and hypoxia [5]. The process comprises several steps including the degradation of the vessel adjacent basement membrane, detachment of the surrounding pericytes and remodeling of the involving extracellular matrix, allowing endothelial cells migration, invasion, proliferation and assembly into tubular structures, promoting endothelial cell anastomosis and vessel branching to create new angiogenic vessels [6].

As revised by Yamaguchi et al., the açaí pulp and seed extracts revealed high levels of antioxidants and bioactive phenolic compounds, such as anthocyanins and other flavonoids (e.g., orientin, isovitexin, scoparin and taxifolin deoxyhexose) [1]. The antioxidant capacity of açaí extracts has been mainly associated with their high content and composition in anthocyanins, water-soluble pigments responsible for the intense purple color of the fruit. The cyanidin-3-O-rutinoside has been identified as the most predominant anthocyanin in purple açaí, followed by cyanidin-3-glycoside and traces of other cyanidin, peonidine and pelargonidin derivatives [7-14].

Nowadays, the dietary sources of antioxidants have been increasingly encouraged in human diet in the context of a healthier lifestyle. Though, the açaí pulp degrades rapidly at room temperature and it is easily prone to post-harvest contaminations [15]. For this reason, the interest on the development of açaí berry dietary supplements (e.g., capsules, lyophilized powder and liquid concentrates) has emerged, in order to reduce the degradation of bioactive compounds during transportation and storage, and even to be incorporated into foods and beverages [1]. However, few information is available about the phenolic composition and health benefits of commercially available dietary açaí supplements, and the impact of industrial processing on bioactive compounds. The comparison of different açaí dietary supplements has demonstrated that they may contain lower contents of phenolic compounds, or even no detectable anthocyanins comparing to non-commercial açaí fruit $[14,16]$. According to Xiong et al., industrially processed fruit exhibited lower proanthocyanidins content (up to approx. 83\%) but higher levels of anthocyanins (20-fold higher) comparing to non-commercial açaí [17].

The present study aimed to investigate the phenolic profile of a purple açaí hydroethanolic extract (AHE) obtained from a commercial dietary powder supplement by high-performance liquid chromatography coupled to diode array detection and electrospray ionization tandem mass spectrometry (HPLC-DAD-ESI-MS ${ }^{n}$ ), and evaluate its potential antioxidant and antiangiogenic mechanisms in human microvascular endothelial cells (HMEC-1). The açaí is mainly commercialized as a powder in many countries, so there is a significant interest in studying this type of dietary supplement as a source of bioactive compounds with health benefits and potential applications as a functional ingredient.

\section{Results and Discussion}

\subsection{Phenolic Profile of AHE by HPLC-DAD-ESI-MS}

The main phytochemicals present in AHE were tentatively identified by HPLC-DADESI-MS $^{n}$. As presented in Figure 1, the obtained chromatograms allowed the identification of 25 phenolic compounds using positive and negative ionization modes, namely anthocyanins and other flavonoids. The tentatively identified compounds are summarized in Tables 1 and 2, and were identified based on bibliographic references, MassBank data and by comparison with standards MS and UV spectra. 


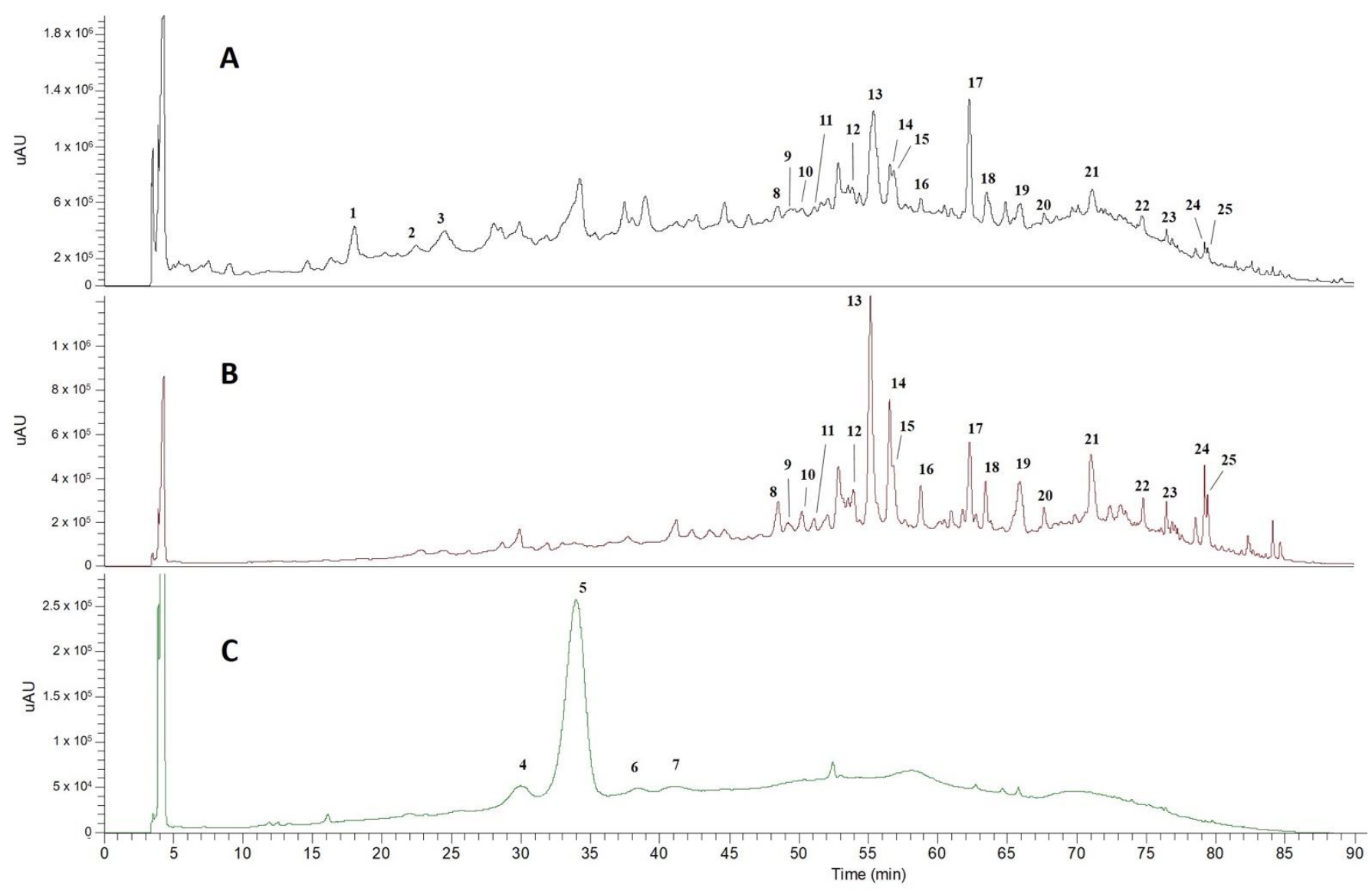

Figure 1. Chromatograms of açaí hydroethanolic extract (AHE) obtained at $280 \mathrm{~nm}$ (A), 340 (B) and 520 (C). Identified signals are presented in Tables 1 and 2.

Table 1. Retention time, maximum absorbance wavelengths and main fragments of anthocyanins tentatively assigned in AHE by HPLC-DAD-ESI-MS ${ }^{n}$, in positive ionization mode. The relative abundance of anthocyanins in AHE is presented as $\%$ of total peak area \pm standard deviation (SD).

\begin{tabular}{|c|c|c|c|c|c|c|}
\hline Peak & $\begin{array}{c}\text { Rt } \\
\text { (Min) }\end{array}$ & $\begin{array}{l}\lambda_{\max } \\
(\mathrm{nm})\end{array}$ & {$[\mathrm{M}]^{+}(m / z)$} & $\begin{array}{c}\text { MS }^{2} \\
\text { Fragment } \\
\text { Ions }(m / z)\end{array}$ & $\begin{array}{c}\text { Proposed } \\
\text { Identification }\end{array}$ & $\begin{array}{c}\text { Peak } \\
\text { Area (\%) }\end{array}$ \\
\hline 4 & 30.6 & 280,517 & 449 & 287 & $\begin{array}{l}\text { Cyanidin-3-O- } \\
\text { glucoside }\end{array}$ & $6.2 \pm 0.3$ \\
\hline 5 & 34.8 & 280,517 & 595 & 449,287 & $\begin{array}{l}\text { Cyanidin-3-O- } \\
\text { rutinoside }\end{array}$ & $89.0 \pm 0.3$ \\
\hline 6 & 38.7 & 280,508 & 579 & 433,271 & $\begin{array}{l}\text { Pelargonidin-3-O- } \\
\text { rutinoside }\end{array}$ & $2.3 \pm 0.1$ \\
\hline 7 & 41.2 & 280,517 & 609 & 463,301 & $\begin{array}{l}\text { Peonidin } \\
\text { 3-O-rutinoside }\end{array}$ & $2.6 \pm 0.5$ \\
\hline
\end{tabular}




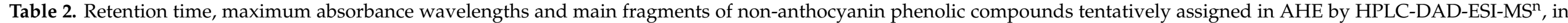
negative ionization mode. The content of phenolic compounds was determined in $\mathrm{mg} / 100 \mathrm{~g} \mathrm{dw}$ and expressed as mean $\pm \mathrm{SD}$.

\begin{tabular}{|c|c|c|c|c|c|c|c|}
\hline Peak & $\begin{array}{c}\text { Rt } \\
\text { (Min) }\end{array}$ & $\begin{array}{l}\lambda_{\max } \\
(\mathrm{nm})\end{array}$ & $\begin{array}{c}{[\mathrm{M}-\mathrm{H}]^{-}} \\
(\mathrm{m} / \mathrm{z})\end{array}$ & $\begin{array}{l}\mathrm{MS}^{2} \underset{(m / z)}{\text { Fragments }} \\
\text {. }\end{array}$ & $\begin{array}{l}\mathrm{MS}^{3} \text { Fragments } \\
(\mathrm{m} / \mathrm{z})\end{array}$ & Proposed Identification & $\begin{array}{c}\text { Content } \\
(\mathrm{mg} / 100 \mathrm{~g} \mathrm{dw})\end{array}$ \\
\hline \multicolumn{8}{|c|}{ Hydroxybenzoic acids } \\
\hline \multicolumn{8}{|c|}{ Proanthocyanidins } \\
\hline 2 & 22.5 & 278 & 865 & $739,713,695,577,425,407$ & - & Proanthocyanidin trimer & $6.3 \pm 0.1^{b}$ \\
\hline 3 & 23.5 & 280 & 577 & $559,451,425,407,289$ & - & $\begin{array}{c}\text { Proanthocyanidin dimer } \\
\text { Total }\end{array}$ & $\begin{array}{l}25.7 \pm 0.4^{\mathrm{b}} \\
32.0 \pm 0.5^{\mathrm{b}}\end{array}$ \\
\hline \multicolumn{8}{|c|}{ Flavonoids } \\
\hline 8 & 48.9 & 277,343 & 593 & $575,503,473,383,353$ & 383,353 & $\begin{array}{l}\text { Apigenin-6,8-di-C-hexoside } \\
\text { (vicenin-2) }\end{array}$ & $4.63 \pm 0.2^{c}$ \\
\hline 9 & 49.6 & 280,340 & 579 & $561,519,489,459,429$ & 399,369 & $\begin{array}{l}\text { Luteolin-6-C-pentoside-8-C-hexoside } \\
\text { isomer } 1\end{array}$ & $1.61 \pm 0.01^{\mathrm{c}}$ \\
\hline 10 & 50.6 & 280,340 & 579 & $561,519,489,459,429$ & 399,369 & $\begin{array}{c}\text { Luteolin-6-C-pentoside-8-C-hexoside } \\
\text { isomer } 2\end{array}$ & $2.47 \pm 0.02^{c}$ \\
\hline 11 & 51.4 & 280,340 & 579 & $561,519,489,459,429$ & 399,369 & \multirow{2}{*}{$\begin{array}{c}\text { Luteolin-6-C-hexoside-8-C-pentoside } \\
\text { Apigenin-6-C-pentoside-8- } \\
\text { C-hexoside }\end{array}$} & $1.40 \pm 0.04^{\mathrm{c}}$ \\
\hline 12 & 54.4 & 280,330 & 563 & $545,503,473,443,383,353$ & 383,353 & & $4.1 \pm 0.1^{\mathrm{c}}$ \\
\hline 15 & 57.3 & 270,346 & 447 & $429,357,327$ & $327,299,285$ & Luteolin-8-C-hexoside (isoorientin) & $5.4 \pm 0.1^{\mathrm{c}}$ \\
\hline 16 & 59.2 & 270,340 & 431 & 341,311 & 283 & Apigenin-8-C-hexoside (vitexin) & $4.79 \pm 0.05^{\mathrm{c}}$ \\
\hline 17 & 62.7 & 290,340 & 287 & $269,259,243$ & $241,215,173,151,125$ & Dihydrokaempferol & $9.6 \pm 0.1^{\mathrm{c}}$ \\
\hline 18 & 64.1 & 274,340 & 461 & 371,341 & 313,298 & Scoparin & $5.14 \pm 0.02^{\mathrm{c}}$ \\
\hline 19 & 66.2 & 274,335 & 689 & $609,591,569$ & $519,489,399,369$ & $\begin{array}{l}\text { Luteolin- } C \text {-hexoside- } C \text {-pentoside } \\
\text { derivative }\end{array}$ & $11.06 \pm 0.05^{c}$ \\
\hline 20 & 68.3 & 274,340 & 533 & 473,443 & 383,353 & Apigenin-6,8-di-C-pentoside & $2.39 \pm 0.02^{c}$ \\
\hline 21 & 71.6 & 275,330 & 673 & $593,575,503$ & $473,383,353$ & Apigenin-di-C-hexoside sulfate & $11.6 \pm 0.2^{c}$ \\
\hline 22 & 75.4 & 280,370 & 301 & $\mathbf{1 7 9}, 151$ & 151 & Quercetin & $2.54 \pm 0.01^{\mathrm{c}}$ \\
\hline 23 & 77.2 & $260,285,350$ & 285 & $241,217,199,175,151,133$ & - & Luteolin & $2.30 \pm 0.06^{\mathrm{c}}$ \\
\hline 24 & 79.8 & 268,350 & 315 & 300 & $283,271,227,151$ & Isorhamnetin & $5.10 \pm 0.04^{\mathrm{c}}$ \\
\hline \multirow[t]{2}{*}{25} & 80.0 & 268,343 & 329 & 314 & 299 & Tricin & $3.46 \pm 0.08^{c}$ \\
\hline & & & & & & Total & $123.3 \pm 0.7^{\mathrm{c}}$ \\
\hline
\end{tabular}


The chromatographic profile of AHE acquired at $520 \mathrm{~nm}$ (Figure 1C) revealed the presence of four main compounds (Peaks 4, 5, 6 and 7 at $\mathrm{Rt}=30.6,34.8$, 38.7 and $41.2 \mathrm{~min}$, respectively). These compounds were undoubtedly identified as anthocyanins by exhibiting a characteristic maximum absorption wavelength at $520 \mathrm{~nm}$ and responsible for the intense purple pigmentation of açaí. The MS analysis was conducted in positive ionization mode since it allowed a better ionization and the selective detection of these compounds (Compounds 4-7, Table 1).

The compounds represented by Peaks 4 and 5 (Figure 1C) were tentatively identified as cyanidin glycoside derivatives, characterized by major ion signals at $m / z 287$ (cyanidin) (Table 1). According to literature, Compounds 4 and 5 were tentatively identified as cyanidin-3-O-rutinoside and cyanidin-3-O-glucoside, respectively [8-11,18-20]. The most abundant anthocyanin identified in AHE was cyanidin-3-O-rutinoside, corresponding to $89 \pm 0.3 \%$ of the total anthocyanins extracted from the açaí dietary supplement (Table 1). In agreement, the identified cyanidin derivatives were also described in high contents in commercial and non-commercial freeze-dried açaí berries, with predominance of cyanidin-3-O-rutinoside [7-11,13,14,19].

Two other anthocyanins were identified in AHE (Figure 1C, Peaks 6 and 7). Peak 6 ( $\mathrm{Rt}=38.7 \mathrm{~min}$ ) exhibited a parent ion at $m / z 609$ and an intense ion at $m / z 301$ in the MS $^{2}$ spectra, corresponding to the anthocyanidin peonidin (Table 1). The compound was tentatively identified as peonidin-3-O-rutinoside $(2.6 \pm 0.5 \%$ of total anthocyanin content) as previously described in açaí fruits from Brazil $[8,9,20]$ and Colombia [11]. Based on previous information published by Garzon et al., Peak 7 (Rt $=41.2 \mathrm{~min}$ ) was tentatively identified as pelargonidin-3-O-rutinoside $(2.3 \pm 0.1 \%$ of total anthocyanin content), and identified in low content in fully ripe açaí pulp (bellow $1 \%$ of total anthocyanins content) [11]. In comparison, cyanidin-3-O-rutinoside was identified as the predominant anthocyanin in different açaí samples (up to $100 \%$ of the total anthocyanins content), followed by cyanidin-3-O-glucoside (up to $19 \%$ ) and peonidin 3-O-rutinoside (up to 4\%) [7-11]. According to this information, the anthocyanins profile of AHE obtained from açaí powder supplement (Figure 1C, Table 1) was found to be very similar to that described for fresh açaí.

A diversity of other non-anthocyanin phenolic compounds was identified in AHE (Table 2).

Peak 1 (Figure 1, Rt = $18.2 \mathrm{~min}$ ) was tentatively identified as protocatechuic acid (dihydroxybenzoic acid) by comparison with commercial standard. The content of protocatechuic acid in AHE ( $9.4 \pm 0.9 \mathrm{mg} / 100 \mathrm{~g} \mathrm{dw})$ was significantly higher comparing to the contents described in the fresh fruit (up to $1.7 \mathrm{mg} / 100 \mathrm{~g} \mathrm{dw}$ ) $[11,13,19]$.

Peaks 2 and 3 (Figure 1, Rt $=22.5 \mathrm{~min}$ and $23.5 \mathrm{~min}$ ) exhibited pseudomolecular ions at $m / z 865$ and 577, respectively (Table 2). These compounds were identified as oligomers of flavan-3-ols (proanthocyanidins). A detailed inspection of the mass spectra of Compound 1 allowed to identify characteristic fragments of a proanthocyanidin trimer. In association, Peak 2 was identified as a dimeric proanthocyanidin [21,22]. According to previous works, proanthocyanidins have been described as one of the major phytochemicals in commercial and non-commercial açaí samples $[9,10,17,19]$. Recently, Martins et al. discovered that Btype and A-type procyanidins were also among the major components in açaí seeds [22]. A detailed inspection of the MS profile of the proanthocyanidins in AHE allowed to conclude that the identified oligomeric forms in the powder supplement were predominantly B-type procyanidins [22]. In our work, the content of proanthocyanidins in AHE were found to be between 6.3 and $25.7 \mathrm{mg}$ catechin/100 $\mathrm{g} \mathrm{dw}$. In comparison, the content of procyanidins in de-seeded fully ripe fruits were reported between 0.7 and $5.3 \mathrm{mg}$ catechin $/ \mathrm{kg}$ [19].

A further investigation of the phenolic compounds in AHE revealed the presence of different flavonoids classes and their corresponding $C$ - and $O$-glycosylated forms (Figure 1A,B; Table 2). The characterization of AHE revealed the presence of flavones as one of the main classes of flavonoids. Peaks 8, 12, 16, 20 and 21 (Figure 1A,B) were tentatively identified as $C$-glycoside conjugates of apigenin (Table 2 ) by the characteristic fragments 
of $C$-glycosylated and di-C-glycosylated flavonoids [23]. The concentration of apigenin derivatives in AHE ranged between 4.1 and $11.6 \mathrm{mg}$ rutin/100 $\mathrm{g} \mathrm{dw}$. In particular, apigenin6,8-di-C-pentoside has not been previously reported in fresh açaí fruit $[11,18,19,24]$, while apigenin-di-C-hexoside sulfate was reported in leaflet extracts of Euterpe oleracea [25].

The flavone luteolin was also identified in AHE (Peak 23, Rt $=77.2 \mathrm{~min}$ ) by a molecular ion at $m / z 285$ (Table 2) and a characteristic fragmentation pattern in $\mathrm{MS}^{2}$ spectra [18]. Peaks 9, 10, 11 (Rt $=49.6,50.6$ and $51.4 \mathrm{~min}$., respectively) showed a pseudomolecular ion at $m / z 579$ and the $\mathrm{MS}^{\mathrm{n}}$ spectra revealed characteristic fragment ions of a di- $C$-asymmetric glycosylated flavone. The ions at $m / z 399$ [aglycone +113$]^{-}$and 369 [aglycone +83$]^{-}$ support the aglycone luteoline [23]. Thus, the compounds were tentatively identified luteolin-C-hexoside- $C$-pentoside isomers (Table 2). Peak 19 revealed a parental ion at $\mathrm{m} / \mathrm{z}$ 689 and a very similar fragmentation pattern comparing to the compounds described previously (Peaks 9-11). However, the obtained information was not enough to propose a reliable identification. Peaks 14 and 15 ( $\operatorname{Tr}=56.9$ and $57.3 \mathrm{~min}$, respectively) were attributed to luteolin- $C$-hexose isomers orientin and isoorientin, respectively, which have been already reported in açaí fruit $[7,11,19,24]$, juice $[18,26]$ and freeze-dried powders [13]. The content of orientin and isoorientin in AHE (12.7 \pm 0.5 and $5.4 \pm 0.1 \mathrm{mg}$ rutin $/ 100 \mathrm{~g} \mathrm{dw}$, respectively) obtained from açaí dietary powder were found to be similar comparing to the previously described contents in açaí pulp ( 15 and $10 \mathrm{mg}$ rutin equivalents/100 $\mathrm{g} \mathrm{dw}$ for orientin and isoorientin, respectively) [11], but around 6-fold lower comparing to the levels reported in other açaí powder dietary supplements [16]. According to Gordon et al., the content of orientin and isoorientin is largely affected by fruit maturation stage and significantly decreases during ripening [13].

Peak $18(\operatorname{Tr}=64.1 \mathrm{~min})$ was also identified as a glycosylated flavone with a deprotonated molecular ion at $m / z 461$ in the mass spectrum. The fragments at $m / z$ $371[\mathrm{M}-\mathrm{H}-90]^{-}$and $341[\mathrm{M}-\mathrm{H}-120]^{-}$are characteristic of scoparin $[10,11,18,19]$.

Peak 25 was tentatively identified as the $O$-methylated flavone tricin, with $[\mathrm{M}-\mathrm{H}]^{-}$ at $m / z 329$ and characteristic fragments at $m / z 314$ and 299 [27]. According to previous studies, the presence of tricin has not been reported in fresh açaí $[11,18,19]$.

Two main flavanonols were identified in AHE by HPLC-DAD-ESI-MS ${ }^{\mathrm{n}}$. One of the most intense peaks identified in the chromatogram at $340 \mathrm{~nm}$ (Figure 1B, Peak 13, $\mathrm{Rt}=55.8 \mathrm{~min}$ ), showed a deprotonated molecule at $m / z 449$ and the $\mathrm{MS}^{\mathrm{n}}$ spectra revealed characteristic fragment ions of the flavanonol taxifolin (Table 2). The compound was identified as taxifolin deoxyhexose, one of the most abundant non-anthocyanin phenolics identified in açaí berries [11,19]. The concentration of taxifolin deoxyhexose in AHE ( $33.1 \pm 0.5 \mathrm{mg}$ rutin/100 g dw) was found to be significantly higher comparing to previously described contents in açaí fresh berries (up to $2.8 \mathrm{mg}$ rutin/100 g dw) [11]. The compound corresponding to Peak $17(\mathrm{Tr}=62.7)$ was attributed to dihydrokaempferol, identified in açaí fruits from Colombia [11] and Brazil [18,24]. Its concentration in AHE was found to be around $9.6 \pm 0.1 \mathrm{mg}$ rutin $/ 100 \mathrm{~g} \mathrm{dw}$, comparing to concentrations ranging between 0.3 and $0.5 \mathrm{mg}$ rutin/100 $\mathrm{g} \mathrm{dw}$ in açaí pulp [11].

Flavonols were also identified in AHE (Table 2, Peaks 22 and 24). The Compound 22 (Figure 1A,B, Rt = $75.4 \mathrm{~min}$ ) showed a fragmentation pattern consistent with quercetin (Table 2) and was previously identified in açaí juice [18] and in freeze-dried açaí powders [28]. The compound represented by Peak 24 (Figure 1) exhibited a pseudomolecular ion at $m / z 315$ and a characteristic fragment ion at $m / z 300$ in the MS $^{2}$ spectra (Table 2). The MS ${ }^{3}$ spectra with a base peak at $m / z 271$ and other typical ions at 283, 227 and 151 allowed to infer about the presence of isorhamnetin [27]. In contrast, Garzon et al. only reported the presence of isorhamnetin-rutinoside in fully ripe açaí pulp [11].

As revealed, it was found that AHE obtained from an açaí dietary powder supplement is an excellent source of bioactive phenolic compounds associated with a broad spectrum of health beneficial effects [1]. Despite the increasing number of studies focused on açaí bioactivity, little is known regarding its angiogenic potential. We have been addressing the in vitro and in vivo effects of diet polyphenols on angiogenesis. We showed that dif- 
ferent classes of phenolic compounds (e.g., beer-derived, coffee and raspberry phenolic compounds) decreased angiogenesis by targeting specific molecular pathways namely VEGF-A, and the underlying signaling pathway, both in physiological and pathological conditions [29-31]. Therefore, the potential in vitro antiangiogenic and antioxidant properties of the phenolic rich AHE were then evaluated.

\subsection{Effect of AHE on Endothelial Cell Viability and Its Antiproliferative Behavior}

In the present study, HMEC-1 treated with AHE were used to evaluate in vitro angiogenic individual steps during vessel sprouting.

The bioactivity of AHE was evaluated on HMEC-1 by studying its possible cytotoxicity effect using MTS (3-[4,5-dimethylthiazol-2-yl]-5-[3-carboxymethoxy-phenyl]-2-[4sulfophenyl]-2H-tetrazolium) viability assay. As depicted in Figure 2A, our results showed that AHE did not exert cytotoxic effects at lower doses, but reduced almost $50 \%$ of mitochondrial activity at the highest concentration tested $(75 \mathrm{mg} / \mathrm{L})$, affecting cellular viability, in comparison to control group ( $p=0.0026)$. In accordance, it has been recently demonstrated that açaí oil induces hepatic and thyroid tissue toxicity in male Wistar rats, after the intake of oil doses higher than $100 \mathrm{mg} / \mathrm{kg}$ for 14 days [32]. In comparison, no genotoxic effects were reported for the same doses in leukocytes, liver, bone marrow and testicular rat cells [33]. The toxic effects registered by histological and histochemical analysis were attributed to palmitic and oleic acids, major constituents of açaí oil, together with vanillic, g-linolenic, linoleic, cinnamic, caffeic, protocatechuic, ferulic, syringic acids, and flavonoids quercetin and kaempferol rutinoside [32,33]. For this reason, the further evaluation of the bioactive properties of AHE was assessed using non-toxic concentrations, in order to consider its pharmacological potential, since some of the compounds reported in fruit oil were also identified in AHE (e.g., protocatechuic acid and quercetin).
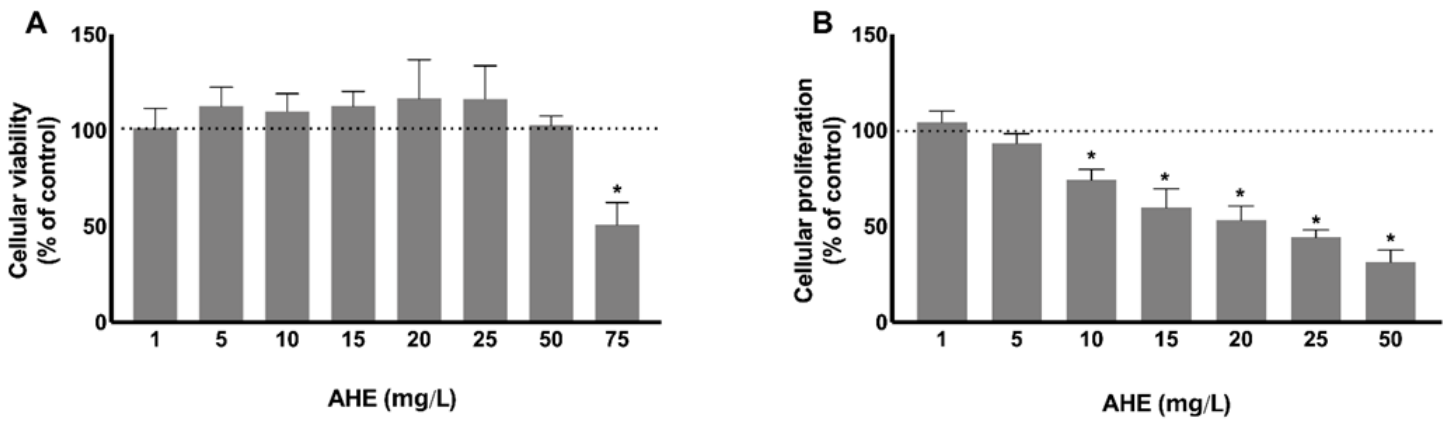

Figure 2. Cytotoxicity and antiproliferative capacity were assessed in HMEC-1 treated with different concentrations of AHE during $24 \mathrm{~h}$. Metabolic activity was determined by MTS assay (A). AHE induces cytotoxicity at the highest concentration tested (75 mg/L), in comparison to control. Proliferation was evaluated by BrdU incorporation (B). There is an inhibition on HMEC-1 proliferation after treatment with AHE, in a dose-dependent manner. Results are expressed as \% of control group. $* p<0.05$ vs. control.

Then, the influence of the extract on the proliferative capacity was assessed by the BrdU incorporation assay in HMEC- 1 incubated with different nontoxic concentrations (1-50 mg/L). Cell proliferation was diminished in a dose-dependent manner. At doses of $10 \mathrm{mg} / \mathrm{L}$ (with a mean decrease of $25.9 \% ; p=0.0005$ ) or higher, a significant decrease in proliferation was observed, when compared with control (Figure 2B). These findings reveal that AHE inhibits endothelial cell proliferative capacity, one major step of the angiogenic process.

\subsection{AHE Decreases Migration and Invasion Potential of Endothelial Cells}

During angiogenesis, cell motility and migration together with extracellular matrix invasion capacity are crucial steps to ensure vessel growth. The influence of AHE on endothelium migration and invasion capacities by wound healing assay and double chamber assay, respectively, was determined after treatment with non-cytotoxic extract concentra- 
tions ranging from 10 to $25 \mathrm{mg} / \mathrm{L}$ (Figure 3A,B). Overnight exposure revealed a decrease in HMEC-1 migration to the injured area, being significant at $25 \mathrm{mg} / \mathrm{L}$ AHE with a reduction of $30.3 \%(p=0.0079)$. This migration inhibitory effect of AHE was accompanied by a reduced capacity of HMEC-1 to invade the extracellular membrane as revealed by the invasion assay.

A

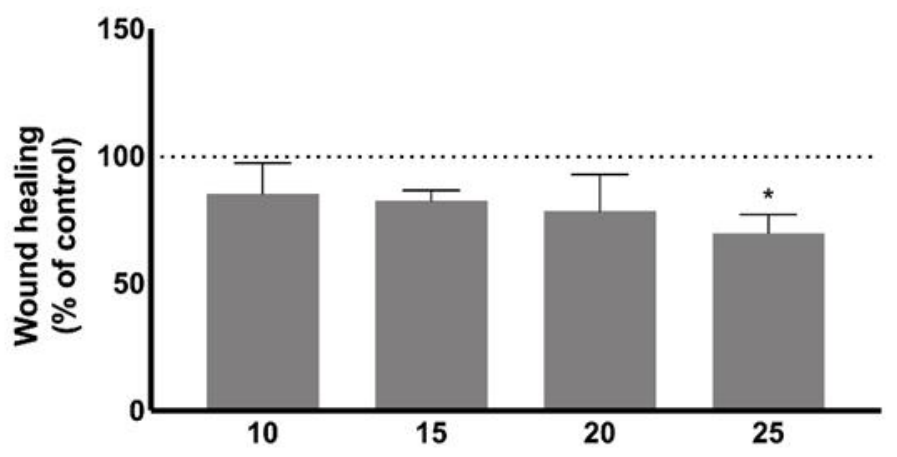

C

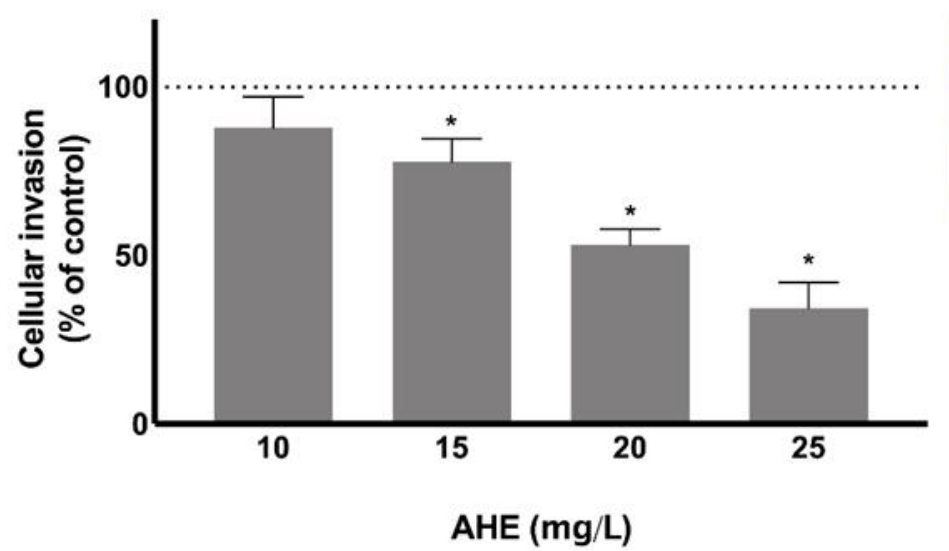

B
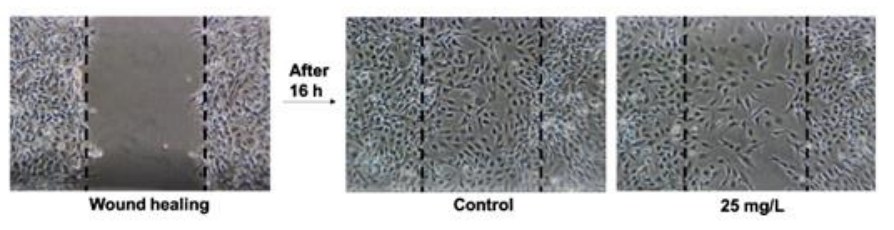

D
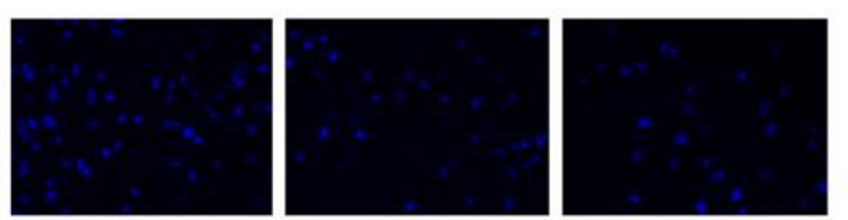

Control $10 \mathrm{mg} / \mathrm{L}$ $15 \mathrm{mg} / \mathrm{L}$

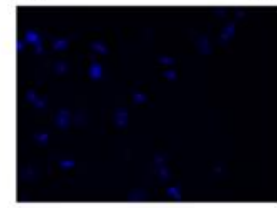

$20 \mathrm{mg} / \mathrm{L}$

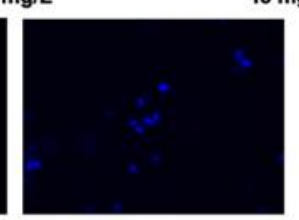

$25 \mathrm{mg} / \mathrm{L}$

Figure 3. The ability to impair HMEC-1 migration and invasion was performed after $16 \mathrm{~h}$ and $24 \mathrm{~h}$ treatment with AHE by injury assay $(\mathbf{A}, \mathbf{B})$ and matrigel-coated transwell assay $(\mathbf{C}, \mathbf{D})$, respectively. There is an abrogation in cell motility and the capacity to migrate to the wound area was reduced at a concentration of $25 \mathrm{mg} / \mathrm{L}$ (A). Dotted lines represent the wound healing area at the beginning of experiment (B). HMEC-1 invasive capacity through a matrigel membrane was reduced in a dose-dependent manner with significance for doses of $15 \mathrm{mg} / \mathrm{L}$ or higher (C). Representative images of invasive HMEC-1 under fluorescence microscope (D). Results are presented as $\%$ of control group mean \pm SD. ${ }^{*} p<0.05$ vs. control.

Accordingly, as shown in Figure 3C,D, when endothelial cells were harvested on a Matrigel-coated transwell permeable chamber and the different treatments were placed on wells below the cell permeable membrane, a dose-dependent effect on the invasion capacity was denoted. A mean reduction of $22.27 \%(p=0.0178), 46.90 \%(p<0.0001)$ and $65.67 \%$ $(p<0.0001)$ at 15,20 , and $25 \mathrm{mg} / \mathrm{L}$ extract concentrations, respectively, was found when compared with control group. These findings indicate that non-cytotoxic concentrations of AHE target migration and invasiveness capacity of HMEC-1, two major features of the angiogenic process.

\subsection{AHE Inhibited the Formation of Capillary-Like Structures Formation}

The effects of AHE on the ability of endothelial cells to assemble into capillary-like structures was also evaluated. As represented in Figure 4A,B, endothelial cells capacity to 
assemble into capillary-like structures and the number of branching points were significantly decreased in a dose-dependent manner for all tested conditions with unconnected structures and loose edges, when compared to control cells that exhibited well-organized and connected tubular structures. The formation of capillary-like structures was reduced between $56.28 \%$ and $91.82 \%$ for AHE concentrations of 10 and $25 \mathrm{mg} / \mathrm{L}$, respectively $(p<0.0001$ vs. control) (Figure 4A,B).

\section{A}

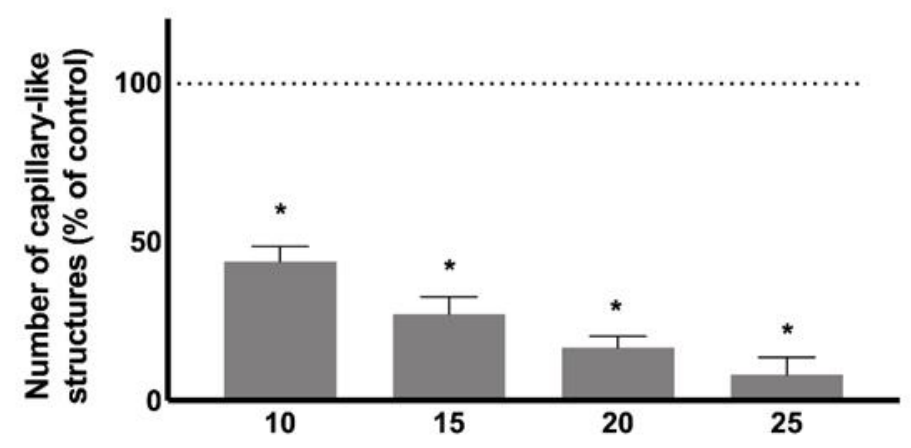

B

$\operatorname{AHE}(\mathrm{mg} / \mathrm{L})$

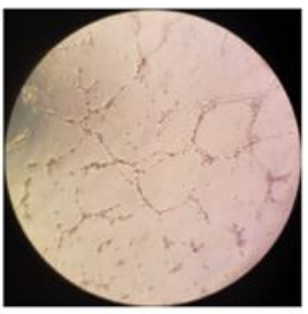

Control

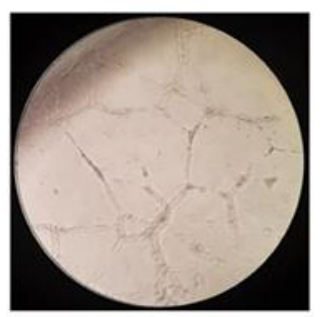

$10 \mathrm{mg} / \mathrm{L}$

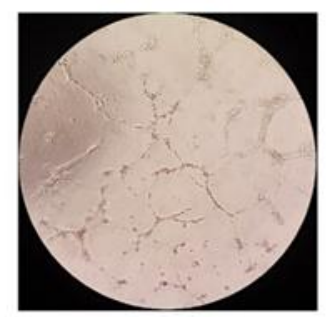

$15 \mathrm{mg} / \mathrm{L}$

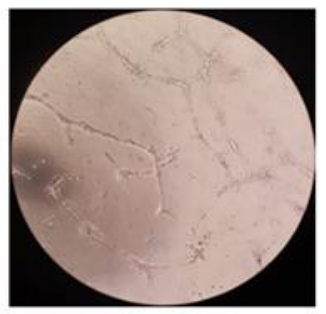

$20 \mathrm{mg} / \mathrm{L}$

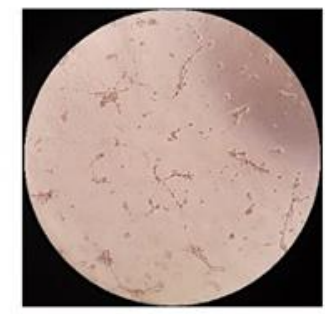

$25 \mathrm{mg} / \mathrm{L}$

Figure 4. Formation of capillary-like structures was quantified in HMEC-1 after treatment with AHE or control, by Matrigel assay. HMEC-1 reduces, dose-dependently, its ability to assemble into tubular structures in concentrations ranging from 10 to $25 \mathrm{mg} / \mathrm{L}$ (A). Representative images of endothelial assembly after $16 \mathrm{~h}$ of standard treatments. (B) Results are expressed as \% of control group. ${ }^{*} p<0.05$ vs. control.

Taken together, our findings demonstrate the antiangiogenic properties of AHE through its effect on fundamental steps of vessel growth. Previous studies on açaí have shown its ability to suppress cancer due to antiangiogenic and anti-inflammatory actions. Alessandra-Perini and colleagues demonstrated a reduction of angiogenic markers, as VEGF and its receptor (VEGFR-2), together with a decrease in pro-inflammatory molecules and activated macrophages in an animal model of breast cancer, treated with $200 \mathrm{mg} / \mathrm{Kg}$ of açaí extract, for 16 weeks [4]. Machado and collaborators also demonstrated an antiangiogenic potential of an AHE at the same dosage, using an animal model of experimental endometriosis. There was a reduction on VEGF levels and metalloproteinase-9 expression, involved in the degradation of basal membrane [3].

\subsection{Antioxidant Potential of AHE on Human Microvascular Endothelial Cells}

Angiogenesis and oxidative stress are intermingled processes and constitute important targets for therapeutic agents, as is the case of natural polyphenols, against cancer, metabolic and cardiovascular diseases, among other pathological conditions.

In order to assess oxidative stress, superoxide dismutase (SOD) and catalase enzymes were quantified due to their importance as endogenous antioxidant defense mechanisms. As illustrated in Figure 5A, SOD activity increased when HMEC-1 were treated 
with AHE. A significant reduction in the percentage of enzymatic inhibition rate was identified in cells treated with $20 \mathrm{mg} / \mathrm{L}(23 \pm 2 \% ; p=0.0094)$ and $25 \mathrm{mg} / \mathrm{L}(22 \pm 4 \%$; $p=0.0068)$ of AHE, in comparison to control group (33.90 $\pm 2.36 \%$ ). Additionally, a dose-dependent increase in the catalase enzymatic activity was observed, as shown in Figure 5B. AHE concentrations of $20 \mathrm{mg} / \mathrm{L}(0.051 \pm 0.005 \mathrm{nmol} / \mathrm{min} / \mathrm{mL} ; p=0.0127)$ and $25 \mathrm{mg} / \mathrm{L}(0.055 \pm 0.002 \mathrm{nmol} / \mathrm{min} / \mathrm{mL} ; p=0.0008)$ increased catalase antioxidant capacity in HMEC-1 versus control group $(0.041 \pm 0.001 \mathrm{nmol} / \mathrm{min} / \mathrm{mL})$.

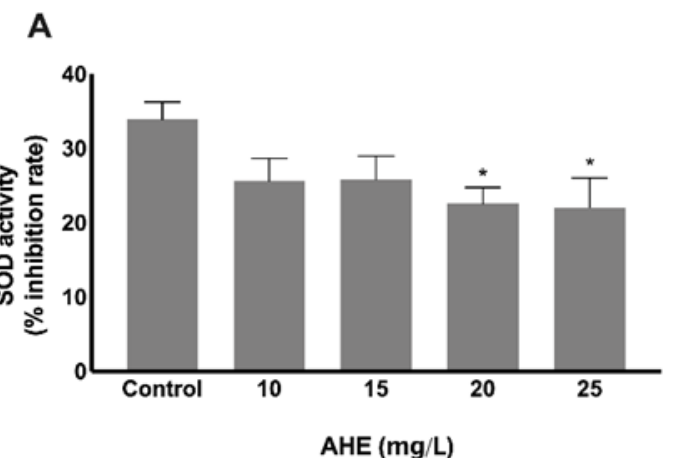

B

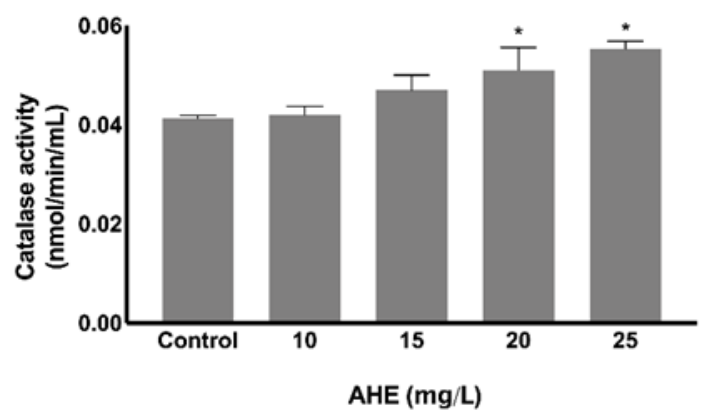

C

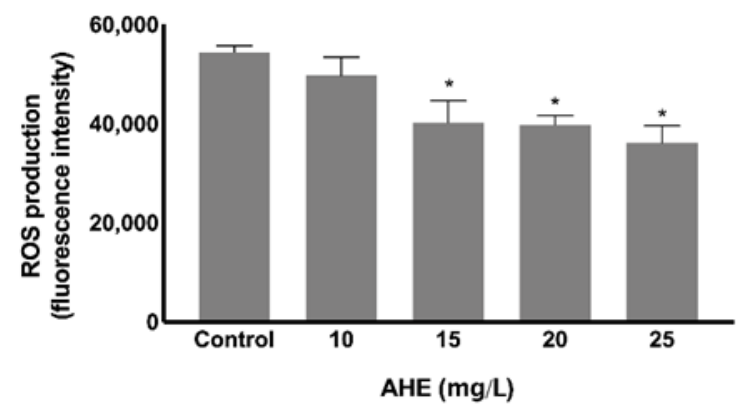

Figure 5. Evaluation of oxidative stress mediators after HMEC-1 treatment with AHE or control. Antioxidant SOD (A) and catalase (B) defenses were both augmented at concentrations of 20 and $25 \mathrm{mg} / \mathrm{L}$, in comparison with control group, analyzed by enzymatic assays. Production of reactive oxygen species (ROS) was reduced dose-dependently, measured after incubation with fluorescence dies, with statistical significance at $15 \mathrm{mg} / \mathrm{L}$ or higher (C). Results are presented as \% inhibition rate of SOD activity (A) nmol of catalase activity $/ \mathrm{min} / \mathrm{mL}(\mathbf{B})$ and units of fluorescence intensity for ROS production $(\mathbf{C}) * p<0.05$ vs. control.

Oxidative stress arises as a result of excessive accumulation of reactive oxygen species (ROS) and reactive nitrogen species (RNS) in the organism, leading to irreversible cellular damage compromising the normal tissue function. In order to evaluate AHE antioxidant properties, a quantification of ROS production was addressed. A dose-dependent reduction on ROS secretion by HMEC-1 was observed upon treatment with AHE doses higher than 
$15 \mathrm{mg} / \mathrm{L}$ (Figure 5C). Cells treated with $15 \mathrm{mg} / \mathrm{L}$ AHE produced significant lower ROS units $(40,204 \pm 4449, p=0.0010)$ in comparison to control (54,446 \pm 1283 ROS units). A more pronounced antioxidant effect was registered when cells were incubated with $20 \mathrm{mg} / \mathrm{L}$ AHE $(39,755 \pm 1903$ ROS units; $p=0.0014)$ and $25 \mathrm{mg} / \mathrm{L}$ AHE $(36,115 \pm 3522$ ROS units; $p<0.0001)$.

Based on the obtained results, SOD and catalase enzymatic activities were increased and ROS production decreased upon AHE treatment. AHE stimulates important antioxidant defenses and reduces free radical levels. Identical achievements were also stated by Schauss et al., reporting an inhibition of ROS formation and a strong SOD activity using human neutrophils, and demonstrating that açaí constituents exert oxygen quenching function inside human cells [34]. Recently, it was found that the administration of an aqueous açaí extract $(3 \mathrm{~g} / \mathrm{Kg})$ during six weeks in mice with non-alcoholic fatty liver disease also improves SOD and catalase activities together with an activation of glutathione reductase [35]. Other studies have associated the consumption of açaí juice with a higher blood antioxidant capacity in healthy volunteers. The consumption of açaí juice by healthy volunteers induced a rapid increase in the systemic antioxidant activity assessed by the cellbased antioxidant protection in erythrocytes assay, with a significant reduction in oxidative damaged within the tissues (e.g., lipid peroxidation) [36] as well as a significant increase of antioxidant enzymes activity (e.g., SOD, catalase and glutathione peroxidase) [37]. In line with these findings, another pilot study reported an increase in blood antioxidant status due to an augment not only on the activity of SOD and catalase but also in other antioxidant enzymes activity (e.g., glutathione peroxidase and reductase) and non-enzymatic oxidant defenses (glutathione), after consumption of an açaí berry-based juice blend for six weeks [38]. Similar achievements were reported in another nutritional intervention study based on the diet supplementation with açaí pulp for 4 weeks. The authors described an increase in catalase and SOD activities and glutathione levels, accompanied by a reduction on ROS production in polymorphonuclear cells, as well as an increment of serum sulfhydryl groups concentration (a marker of antioxidant capacity) [39].

The oxidative protective effects here described may be attributed to the presence of anthocyanins in AHE, predominantly cyanidin-3-O-rutoside and cyanidin-3-O-glucoside, as found by Jensen et al. [36]. In fact, anthocyanins have been described as the main contributors for açaí antioxidant properties [7,12,26,40,41]. Açaí pulp extracts, rich in anthocyanins, also exhibit health beneficial properties (e.g., neuroprotective and cardioprotective) by mechanisms dependent on their antioxidant properties [42-44]. Both cyanidin-3-Orutinoside and cyanidin-3-O-glucoside, identified as the main anthocyanins in AHE, have demonstrated protective effects on neuroblastoma SH-SY5Y cells [44] and reduced necrotic glial cell death in oxidative stress conditions [45].

\section{Materials and Methods}

\subsection{Chemicals}

Rutin hydrate (95\%), (+)-catechin hydrate (98\%) and protocatechuic acid (97\%), used in chromatographic analysis, were purchased from Sigma (St. Louis, MO, USA). Highpurity water was obtained from a Direct-Q 3 UV water purification system (Millipore Iberian, Spain) and used for all analyses and glassware washing. Ethanol (EtOH, 96\%) for the extractions was purchased from Chem-Lab (Zedelgem, Belgium). Methanol (MeOH) for (ultra-high pressure liquid chromatography) UHPLC Supergradient was obtained from PanReac AppliChem (Darmstadt, Germany). Formic acid (LiChropur ${ }^{\mathrm{TM}}, 98 \%$ ) used in chromatographic and mass spectrometry analyses was purchased from Sigma-Aldrich (St. Louis, MO, USA). The culture medium RPMI 1640 and all reagents used in biological assays were also purchased from Sigma-Aldrich with the maximum purity available. RIPA (Radio-Immunoprecipitation Assay) buffer was from Chemicon International (Temecula, CA, USA). All other reagents used were of analytical grade quality or higher. 


\subsection{Sample and Extract Preparation}

The commercial organic açai fruit powder was obtained directly from the producer (Lisboa, Portugal) and freeze-dried after reception in order to remove any residual water content. Extraction was performed by mixing $1.0 \mathrm{~g}$ of freeze-dried fruit powder with $10 \mathrm{~mL}$ of EtOH: $\mathrm{H}_{2} \mathrm{O}(70: 30, v / v)$. The extraction was performed 3 times during 30 min under stirring. The AHE was centrifuged (10 $\mathrm{min}$ at $6000 \mathrm{rpm})$ and the supernatant was filtered using regenerated cellulose syringe filters (Sartorius Minisart ${ }^{\circledR} \mathrm{RC} 0.45 \mu \mathrm{m}$, Goettingen, Germany). The solvent was then evaporated in a rotary evaporator (Hei-Vap precision, Heidolph, Schwabach, Germany), and the remaining water was removed by lyophilization (Unicryo MC4L, UniEquip, Martinsried, Germany). The obtained residue was redissolved in appropriate solvents at the desired concentrations for further studies.

\subsection{HPLC-DAD-ESI-MS ${ }^{n}$ Analysis}

The chemical characterization of AHE was performed by high performance liquid chromatography coupled with an ion-trap mass spectrometer and a diode array detector. For the study, the freeze-dried AHE was dissolved in $\mathrm{MeOH}: \mathrm{H}_{2} \mathrm{O}(50: 50, v / v)$ in a concentration of $30 \mathrm{~g} / \mathrm{L}$ and filtered using RC syringe filters (Sartorius Minisart ${ }^{\circledR} \mathrm{RC}$ $0.45 \mu \mathrm{m}$, Goettingen, Germany) previously to injection. The HPLC system (Thermo Electron Corporation, Waltham, MA, USA) consisted of a low-pressure quaternary pump with autosampler and a diode array detector (Finnigan Surveyor Plus, Thermo Fisher Scientific). Separations were carried out on a Phenomenex (Torrance, CA, USA) GeminiNX C18 column $(150 \mathrm{~mm} \times 4.6 \mathrm{~mm} ; 3 \mu \mathrm{m})$ and a guard column $(4 \mathrm{~mm} \times 3.0 \mathrm{~mm})$. The chromatographic conditions were the following: flow rate $0.4 \mathrm{~mL} / \mathrm{min}$, sample injection volume $25 \mu \mathrm{L}$, and a binary mobile phase (A, $\mathrm{MeOH}$ and $\mathrm{B}, 0.1 \%$ aqueous formic acid). A gradient program was used as follows: 0 to $40 \mathrm{~min}$, linear increase from $10 \%$ to $30 \%$ of $\mathrm{A}, 40$ to $60 \mathrm{~min}$, increase to $45 \%$ of $\mathrm{A}, 60$ to $90 \mathrm{~min}$, linear increase to $100 \% \mathrm{~A}$ and conditions maintained for $5 \mathrm{~min}$; return to initial conditions in $15 \mathrm{~min}$ and conditions maintained for $10 \mathrm{~min}$ before the next injection. A quadrupole ion-trap mass spectrometer (Finnigan LCQ Deca XP Plus) coupled with an electrospray ionization (ESI) source was used. Data acquisition was performed in positive and negative ion modes in the range $150-1000 \mathrm{~m} / \mathrm{z}$. The interface conditions were applied as follows: capillary temperature, $325^{\circ} \mathrm{C}$; source voltage, $5.0 \mathrm{kV}$; capillary voltage, $-15.0 \mathrm{~V}$ for negative mode and $4 \mathrm{~V}$ for positive mode; sheath gas $\left(\mathrm{N}_{2}\right)$ flow at 60 arbitrary units and auxiliary gas $\left(\mathrm{N}_{2}\right)$ flow at 23 arbitrary units. Tandem mass spectrometric studies were performed ( $\mathrm{MS}^{2}$ and $\mathrm{MS}^{3}$ ). For the $\mathrm{MS}^{\mathrm{n}}$ analyses activation energy of $45 \%$ was applied. The pseudomolecular ions were fragmented by collision-induced dissociation (CID) with the nitrogen collision gas in the ion trap. The diode array detection was conducted by scanning between 200 and $600 \mathrm{~nm}$. The identification of the compounds was performed by comparison of the spectral results with commercial standards and literature information Data acquisition and processing was achieved by using Xcalibur software version 2.1.0 (Finnigan, San Jose, CA, USA).

The contents of individual phenolic compounds (expressed in mg per $100 \mathrm{~g}$ of açaí powder dry-weight $(\mathrm{dw})$ ) were determined by the external standard method using calibration curves of available commercial standards or ones with similar structure: rutin $\left(\mathrm{y}=342703 \mathrm{x}-8273, \mathrm{r}^{2}=0.9999\right.$, limit of detection $(\mathrm{LOD})=0.16 \mathrm{mg} / \mathrm{L}$ and limit of quantification $(\mathrm{LOQ})=0.54 \mathrm{mg} / \mathrm{L}) ;$ catechin $\left(\mathrm{y}=148109 \mathrm{x}+895, \mathrm{r}^{2}=0.9999, \mathrm{LOD}=0.10 \mathrm{mg} / \mathrm{L}\right.$ and $\mathrm{LOQ}=0.34 \mathrm{mg} / \mathrm{L})$; protocatechuic acid $\left(\mathrm{y}=395222 \mathrm{x}-1885, \mathrm{r}^{2}=0.9997, \mathrm{LOD}=0.37 \mathrm{mg} / \mathrm{L}\right.$ and $\mathrm{LOQ}=1.23 \mathrm{mg} / \mathrm{L}$ ). The anthocyanins abundance in AHE was determined based on the comparison of relative peak areas.

\subsection{Cell Culture Experiments}

Human microvascular endothelial cells (HMEC-1; ATCC, Barcelona, Spain) were used between passages 3 and 7. HMEC- 1 were cultured in RPMI 1640 medium supplemented with $10 \%$ FBS, $1 \%$ penicillin/streptomycin, $1.176 \mathrm{~g} / \mathrm{L}$ of sodium bicarbonate, $4.76 \mathrm{~g} / \mathrm{L}$ of Hepes, $1 \mu \mathrm{g} / \mathrm{L}$ of EGF and $1 \mathrm{mg} / \mathrm{L}$ of hydrocortisone, and maintained at $37^{\circ} \mathrm{C}$ in 
a humidified $5 \% \mathrm{CO}_{2}$ atmosphere. Treatments were performed during 16 or $24 \mathrm{~h}$ in serum-free conditions. The freeze-dried AHE was dissolved in $\mathrm{EtOH}: \mathrm{H}_{2} \mathrm{O}(70: 30, v / v)$ in a concentration of $20 \mathrm{~g} / \mathrm{L}$, diluted in serum-free culture medium and added to cell cultures at final concentrations ranging the doses 1 to $75 \mathrm{mg} / \mathrm{L}$. Controls were performed using $0.7 \% \mathrm{EtOH}$.

\subsection{MTS Toxicity Assay}

HMEC-1 $\left(2 \times 10^{5}\right.$ cells $\left./ \mathrm{mL}\right)$ were allowed to grow until 70-90\% confluence and then incubated with each treatment for $24 \mathrm{~h}$. Cellular viability was assessed using Cell Titer 96 ${ }^{\circledR}$ Aqueous ONE Solution Reagent (MTS, [3-(4,5-dimethylthiazol-2-yl)-5-(3carboxymethoxyphenyl)-2-(4-sulfophenyl)-2H-tetrazolium] colorimetric assay (Promega, Madison, EUA), according to the instructions provided by the manufacturer. Optical density was measured at $492 \mathrm{~nm}$ in a microplate reader (Multiskan Ascent, Thermo Electron Corporation, Waltham, MA, USA). Results are expressed as percentage of control, which was considered to be $100 \%$.

\subsection{BrdU Proliferation Assay}

HMEC-1 $\left(2 \times 10^{5}\right.$ cells $\left./ \mathrm{mL}\right)$ were allowed to grow until 70-90\% confluence and then incubated with each treatment for $24 \mathrm{~h}$. Cells were treated with the non-cytotoxic concentrations of AHE and incubated with a 5'-bromodeoxyuridine (BrdU) solution and then the in situ detection was performed using an In-Situ Detection Kit (Roche, Amadora, Portugal), according to manufacturer's instructions. Results are expressed as percentage of control, which was considered to be $100 \%$.

\subsection{Migration Analysis}

To perform injury assay cells were grown to $90 \%$ confluence and were scrapped from the culture dish using a pipette tip, leaving a void space. Cells were then incubated for $16 \mathrm{~h}$ with the distinct treatments. Cell migration to the damaged area was visualized and photographed on a phase contrast microscope (Nikon, UK), at a magnification of $\times 200$ and quantified using ImageJ software (LOCI, Madison, WI, USA). Results are expressed as percentage of control, which was considered to be $100 \%$.

\subsection{Invasion Assay}

The invasion cell capacity of HMEC-1 in the presence of AHE was then quantified by counting the number of cells that migrated through matrigel-coated transwell $(8 \mu \mathrm{m}$ pore-size; BD-biosciences, San Jose, CA, USA). Cells $\left(5 \times 10^{4}\right.$ cells $\left./ \mathrm{mL}\right)$ were harvested on inserts in serum-free medium and placed on wells containing medium complemented with a chemoattractant (FBS 10\%), with the distinct treatments. After incubation for $24 \mathrm{~h}$, membranes were removed from inserts, stained with DAPI-MeOH and visualized under a fluorescence microscope (Zeiss ApoTome, Zaventem, Belgium). Twenty random fields of each membrane were counted, at a magnification of $\times 200$. Results are expressed as percentage of control, which was considered to be $100 \%$.

\subsection{Matrigel Assay for Evaluation of Capillary-Like Structures Formation}

HMEC-1 were incubated with the distinct treatments and added to matrigel-coated plates (BD-biosciences, San Jose, CA, USA). After $16 \mathrm{~h}$ of incubation, the number of capillary-like structures was counted in a phase-contrast microscope (Nikon, Surrey, UK), at a magnification of $\times 200$. Each cord portion between ramifications was considered as one capillary-like structure. Results are expressed as percentage of control, which was considered to be $100 \%$. 


\subsection{Evaluation of Antioxidant Capacity in HMEC-1}

\subsubsection{Superoxide Dismutase Activity}

The superoxide dismutase (SOD) activity was evaluated in HMEC-1 lysates $\left(3 \times 10^{4}\right.$ cells $\left./ \mathrm{mL}\right)$ after cell incubation with the distinct experimental conditions. Cell lysis was performed using RIPA buffer and protein content was quantified by Pierce ${ }^{\mathrm{TM}}$ BCA protein assay kit (Thermo Fisher Scientific, Waltham, MA, USA). The percentage of inhibition rate of SOD activity was addressed by SOD determination kit (Sigma Aldrich, St. Louis, MO, USA), according to the manufacturer's instructions. Results are expressed as the $\%$ inhibition rate in comparison to control, which was considered to be $100 \%$.

\subsubsection{Catalase Activity}

Catalase activity was assessed in cell lysates, prepared as described in 2.10.1, with a colorimetric Catalase Activity Assay Kit (Abcam, Cambridge, UK), according to manufacturer instructions. Catalase activity is expressed as $\mathrm{nmol} / \mathrm{min} / \mathrm{mL}$.

\subsubsection{Reactive Oxygen Species Formation}

Reactive oxygen species (ROS) generation by HMEC-1, assessed in cell supernatants after treatment with AHE, was performed using $2^{\prime}, 7^{\prime}$-dichlorofluorescin diacetate (DCFDA)ROS detection kit (DCFDA Cellular ROS Detection Kit, Abcam, UK) according to manufacturer instructions. Results are expressed as means of fluorescence units \pm SD.

\subsection{Statistical Analysis}

Results are expressed as the mean \pm standard deviation (SD) of three independent experiments. For comparison of the distinct experimental groups, analysis of variance (ANOVA test) followed by the Bonferroni pos-hoc test was used. A difference between experimental groups was considered statistically significant whenever $p$ value was $<0.05$.

\section{Conclusions}

Nowadays, natural products assume a relevant role considering their safety and health-promoting properties. The results here presented clearly demonstrate that açaí fruit freeze-dried powder is a source of angiogenic inhibitors and antioxidant compounds. The chemical characterization of AHE revealed the presence of anthocyanins and flavonoids as major constituents, with the capacity to inhibit endothelial cells migration and the formation of capillary-like structures, with no cytotoxic effects. The anti-angiogenic activity was associated with a reduction of ROS production and an increase of antioxidant enzymatic defenses regulated by SOD and catalase. This is of particular importance concerning the application of AHE for the development of drugs and nutraceuticals as novel therapeutic approaches for angiogenesis-dependent diseases, and also as valuable source of bioactive components for cosmetic products. Nevertheless, further studies should focus on the identification of the main phytochemicals associated with the observed effects among the described molecules, and on the evaluation of its isolated activity as well as possible synergistic effects. Additionally, in vivo studies would have a relevant interest considering possible cytotoxic effects related with the intake of AHE. Further studies may also encompass other commercial açaí products and dietary supplements in order to understand the impact of industrial processing on their chemical profile, bioactivity and health benefits, in comparison to fresh açaí fruit.

Author Contributions: Conceptualization, R.C., P.B. and D.O.C.; methodology, R.C. and D.A.; validation, R.C., D.A. and D.O.C.; formal analysis, R.C.; investigation, R.C., D.A. and D.O.C.; resources, P.B.; data curation, R.C., D.A. and D.O.C.; writing-original draft preparation, R.C. and D.O.C.; writing-review and editing, R.C., R.S., L.F.G. and D.O.C.; visualization, R.C., D.A. and D.O.C.; supervision, R.C. and D.O.C.; funding acquisition, R.S. and L.F.G. All authors have read and agreed to the published version of the manuscript. 
Funding: This research was funded by FCT/MEC through national funds and co-funded by FEDER, grants number UIDB/50006/2020 and NORTE-01-0145-FEDER-000012. D.O.C. thanks the research grant through the project UIDB/QUI/50006/2020. R.C. acknowledges FCT for funding through the project NORTE-01-0145-FEDER-000012.

Data Availability Statement: The data presented in this study are available within the article.

Acknowledgments: The authors thank Dra. Zélia Martins Azevedo for her support conducting the HPLC-DAD-MS/MS analyses.

Conflicts of Interest: The authors declare no conflict of interest.

Sample Availability: Samples of the compounds are not available from the authors.

\section{References}

1. Yamaguchi, K.K.D.L.; Pereira, L.F.R.; Lamarão, C.V.; Lima, E.S.; da Veiga-Junior, V.F. Amazon acai: Chemistry and biological activities: A review. Food Chem. 2015, 179, 137-151. [CrossRef]

2. De Almeida Magalhães, T.S.; de Oliveira Macedo, P.C.; Converti, A.; Neves de Lima, Á.A. The Use of Euterpe oleracea Mart. As a New Perspective for Disease Treatment and Prevention. Biomolecules 2020, 10, 813. [CrossRef]

3. Machado, D.E.; Rodrigues-Baptista, K.C.; Alessandra-Perini, J.; De Moura, R.S.; Dos Santos, T.A.; Pereira, K.G.; Da Silva, Y.M.; Souza, P.J.C.; Nasciutti, L.E.; Perini, J.A. Euterpe oleracea Extract (Açaí) Is a Promising Novel Pharmacological Therapeutic Treatment for Experimental Endometriosis. PLoS ONE 2016, 11, e0166059. [CrossRef]

4. Alessandra-Perini, J.; Perini, J.A.; Rodrigues-Baptista, K.C.; De Moura, R.S.; Junior, A.P.; Dos Santos, T.A.; Souza, P.J.C.; Nasciutti, L.E.; Machado, D.E. Euterpe oleracea extract inhibits tumorigenesis effect of the chemical carcinogen DMBA in breast experimental cancer. BMC Complement. Altern. Med. 2018, 18, 116. [CrossRef]

5. Folkman, J. Angiogenesis: An organizing principle for drug discovery? Nat. Rev. Drug Discov. 2007, 6, 273-286. [CrossRef]

6. Carmeliet, P.; Jain, R.K. Molecular mechanisms and clinical applications of angiogenesis. Nat. Cell Biol. 2011, 473, $298-307$. [CrossRef]

7. Carvalho, A.V.; Da Silveira, T.F.F.; Mattietto, R.D.A.; De Oliveira, M.D.S.P.; Godoy, H.T. Chemical composition and antioxidant capacity of açaí (Euterpe oleracea) genotypes and commercial pulps. J. Sci. Food Agric. 2016, 97, 1467-1474. [CrossRef]

8. De Rosso, V.V.; Hillebrand, S.; Montilla, E.C.; Bobbio, F.O.; Winterhalter, P.; Mercadante, A.Z. Determination of anthocyanins from acerola (Malpighia emarginata DC.) and açai (Euterpe oleracea Mart.) by HPLC-PDA-MS/MS. J. Food Compos. Anal. 2008, 21, 291-299. [CrossRef]

9. Lichtenthaler, R.; Rodrigues, R.B.; Maia, J.G.; Papagiannopoulos, M.; Fabricius, H.; Marx, F. Total oxidant scavenging capacities of Euterpe oleracea Mart. (Acai) fruits. Int. J. Food Sci. Nutr. 2005, 56, 53-64. [CrossRef]

10. Schauss, A.G.; Wu, X.; Prior, R.L.; Ou, B.; Patel, D.; Huang, D.; Kababick, J.P. Phytochemical and Nutrient Composition of the Freeze-Dried Amazonian Palm Berry, Euterpe oleraceae Mart. (Acai). J. Agric. Food Chem. 2006, 54, 8598-8603. [CrossRef]

11. Garzón, G.A.; Narváez-Cuenca, C.-E.; Vincken, J.-P.; Gruppen, H. Polyphenolic composition and antioxidant activity of açai (Euterpe oleracea Mart.) from Colombia. Food Chem. 2017, 217, 364-372. [CrossRef] [PubMed]

12. Del Pozo-Insfran, D.; Brenes, C.H.; Talcott, S.T. Phytochemical Composition and Pigment Stability of Açai (Euterpe oleracea Mart.). J. Agric. Food. Chem. 2004, 52, 1539-1545. [CrossRef] [PubMed]

13. Gordon, A.; Gil Cruz, A.P.; Cabral, L.M.C.; de Freitas, S.C.; Taxi, C.M.A.D.; Donangelo, C.M.; Mattietto, R.D.A.; Friedrich, M.; da Matta, V.M.; Marx, F. Chemical characterization and evaluation of antioxidant properties of Açaí fruits (Euterpe oleraceae Mart.) during ripening. Food Chem. 2012, 133, 256-263. [CrossRef]

14. Matta, F.V.; Xiong, J.; Lila, M.A.; Ward, N.I.; Felipe-Sotelo, M.; Esposito, D. Chemical Composition and Bioactive Properties of Commercial and Non-Commercial Purple and White Açaí Berries. Foods 2020, 9, 1481. [CrossRef]

15. de Jesus, A.L.T.; Cristianini, M.; dos Santos, N.M.; Maróstica Júnior, M.R. Effects of high hydrostatic pressure on the microbial inactivation and extraction of bioactive compounds from açaí (Euterpe oleracea Martius) pulp. Food Res. Int. 2020, $130,108856$. [CrossRef] [PubMed]

16. Earling, M.; Beadle, T.; Niemeyer, E.D. Açai Berry (Euterpe oleracea) Dietary Supplements: Variations in Anthocyanin and Flavonoid Concentrations, Phenolic Contents, and Antioxidant Properties. Plant Foods Hum. Nutr. 2019, 74, 421-429. [CrossRef]

17. Xiong, J.; Matta, F.V.; Grace, M.; Lila, M.A.; Ward, N.I.; Felipe-Sotelo, M.; Esposito, D. Phenolic content, anti-inflammatory properties, and dermal wound repair properties of industrially processed and non-processed acai from the Brazilian Amazon. Food Funct. 2020, 11, 4903-4914. [CrossRef]

18. Dias, A.L.S.; Rozet, E.; Larondelle, Y.; Hubert, P.; Rogez, H.; Quetin-Leclercq, J. Development and validation of an UHPLC-LTQOrbitrap MS method for non-anthocyanin flavonoids quantification in Euterpe oleracea juice. Anal. Bioanal. Chem. 2013, 405, 9235-9249. [CrossRef]

19. Pacheco-Palencia, L.A.; Duncan, C.E.; Talcott, S.T. Phytochemical composition and thermal stability of two commercial açai species, Euterpe oleracea and Euterpe precatoria. Food Chem. 2009, 115, 1199-1205. [CrossRef] 
20. Dias, A.; Rozet, E.; Chataigné, G.; Oliveira, A.; Rabelo, C.; Hubert, P.; Rogez, H.; Quetin-Leclercq, J. A rapid validated UHPLCPDA method for anthocyanins quantification from Euterpe oleracea fruits. J. Chromatogr. B 2012, 907, 108-116. [CrossRef]

21. Friedrich, W.; Eberhardt, A.; Galensa, R. Investigation of proanthocyanidins by HPLC with electrospray ionization mass spectrometry. Eur. Food Res. Technol. 2000, 211, 56-64. [CrossRef]

22. Martins, G.R.; Amaral, F.R.L.D.; Brum, F.L.; Mohana-Borges, R.; de Moura, S.S.; Ferreira, F.A.; Sangenito, L.S.; Santos, A.L.; Figueiredo, N.G.; da Silva, A.S. Chemical characterization, antioxidant and antimicrobial activities of açaí seed (Euterpe oleracea Mart.) extracts containing A- and B-type procyanidins. LWT 2020, 132, 109830. [CrossRef]

23. Geng, P.; Sun, J.; Zhang, M.; Li, X.; Harnly, J.M.; Chen, P. Comprehensive characterization of C-glycosyl flavones in wheat (Triticum aestivum L.) germ using UPLC-PDA-ESI/HRMS(n) and mass defect filtering. J. Mass Spectrom. 2016, 51, 914-930. [CrossRef]

24. Kang, J.; Li, Z.; Wu, T.; Jensen, G.S.; Schauss, A.G.; Wu, X. Anti-oxidant capacities of flavonoid compounds isolated from acai pulp (Euterpe oleracea Mart.). Food Chem. 2010, 122, 610-617. [CrossRef]

25. Brunschwig, C.; Leba, L.-J.; Saout, M.; Martial, K.; Bereau, D.; Robinson, J.-C. Chemical Composition and Antioxidant Activity of Euterpe oleracea Roots and Leaflets. Int. J. Mol. Sci. 2016, 18, 61. [CrossRef] [PubMed]

26. Da Silveira, T.F.F.; Cristianini, M.; Kuhnle, G.G.; Ribeiro, A.B.; Filho, J.T.; Godoy, H.T. Anthocyanins, non-anthocyanin phenolics, tocopherols and antioxidant capacity of açaí juice (Euterpe oleracea) as affected by high pressure processing and thermal pasteurization. Innov. Food Sci. Emerg. Technol. 2019, 55, 88-96. [CrossRef]

27. Kang, J.; Price, W.E.; Ashton, J.; Tapsell, L.C.; Johnson, S. Identification and characterization of phenolic compounds in hydromethanolic extracts of sorghum wholegrains by LC-ESI-MS(n). Food Chem. 2016, 211, 215-226. [CrossRef]

28. Mulabagal, V.; Calderón, A.I. Liquid chromatography/mass spectrometry based fingerprinting analysis and mass profiling of Euterpe oleracea (açaí) dietary supplement raw materials. Food Chem. 2012, 134, 1156-1164. [CrossRef]

29. Costa, R.; Rodrigues, I.; Guardão, L.; Lima, J.Q.; Sousa, E.; Soares, R.; Negrão, R. Modulation of VEGF signaling in a mouse model of diabetes by xanthohumol and 8-prenylnaringenin: Unveiling the angiogenic paradox and metabolism interplay. Mol. Nutr. Food Res. 2017, 61, 4. [CrossRef]

30. Moeenfard, M.; Cortez, A.; Machado, V.; Costa, R.; Luís, C.; Coelho, P.; Soares, R.; Alves, A.; Borges, N.; Santos, A. Anti-Angiogenic Properties of Cafestol and Kahweol Palmitate Diterpene Esters. J. Cell. Biochem. 2016, 117, 2748-2756. [CrossRef]

31. Sousa, M.; Machado, V.; Costa, R.; Figueira, M.E.; Sepodes, B.; Barata, P.; Ribeiro, L.; Soares, R. Red Raspberry Phenols Inhibit Angiogenesis: A Morphological and Subcellular Analysis Upon Human Endothelial Cells. J. Cell. Biochem. 2015, 117, 1604-1612. [CrossRef]

32. Marques, E.d.S.; Froder, J.G.; Oliveira, P.R.d.; Perazzo, F.F.; Rosa, P.C.P.; Gaivão, I.O.N.d.M.; Mathias, M.I.C.; Maistro, E.L. Cytotoxic effects of Euterpe oleraceae fruit oil (açaí) in rat liver and thyroid tissues. Rev. Bras. Farmacogn. 2019, $29,54-61$. [CrossRef]

33. Marques, E.; Froder, J.; Carvalho, J.; Rosa, P.; Perazzo, F.; Maistro, E. Evaluation of the genotoxicity of Euterpe oleraceae Mart. (Arecaceae) fruit oil (açaí), in mammalian cells in vivo. Food Chem. Toxicol. 2016, 93, 13-19. [CrossRef] [PubMed]

34. Schauss, A.G.; Wu, X.; Prior, R.L.; Ou, B.; Huang, D.; Owens, J.; Agarwal, A.; Jensen, G.S.; Hart, A.N.; Shanbrom, E. Antioxidant Capacity and Other Bioactivities of the Freeze-Dried Amazonian Palm Berry, Euterpe oleraceaeMart. (Acai). J. Agric. Food Chem. 2006, 54, 8604-8610. [CrossRef]

35. Carvalho, M.M.D.F.; Lage, N.N.; Paulino, A.H.D.S.; Pereira, R.R.; De Almeida, L.T.; Da Silva, T.F.; Magalhães, C.L.D.B.; De Lima, W.G.; Silva, M.E.; Pedrosa, M.L.; et al. Effects of açai on oxidative stress, ER stress, and inflammation-related parameters in mice with high fat diet-fed induced NAFLD. Sci. Rep. 2019, 9, 1-11. [CrossRef]

36. Jensen, G.S.; Wu, X.; Patterson, K.M.; Barnes, J.; Carter, S.G.; Scherwitz, L.; Beaman, R.; Endres, J.R.; Schauss, A.G. In Vitro and in Vivo Antioxidant and Anti-inflammatory Capacities of an Antioxidant-Rich Fruit and Berry Juice Blend. Results of a Pilot and Randomized, Double-Blinded, Placebo-Controlled, Crossover Study. J. Agric. Food Chem. 2008, 56, 8326-8333. [CrossRef] [PubMed]

37. De Liz, S.; Cardoso, A.L.; Copetti, C.L.K.; Hinnig, P.D.F.; Vieira, F.G.K.; da Silva, E.L.; Schulz, M.; Fett, R.; Micke, G.A.; Di Pietro, P.F. Açaí (Euterpe oleracea Mart.) and juçara (Euterpe edulis Mart.) juices improved HDL-c levels and antioxidant defense of healthy adults in a 4-week randomized cross-over study. Clin. Nutr. 2020, 39, 3629-3636. [CrossRef]

38. Sadowska-Krepa, E.; Kłapcińska, B.; Podgórski, T.; Szade, B.; Tyl, K.; Hadzik, A. Effects of supplementation with acai (Euterpe oleracea Mart.) berry-based juice blend on the blood antioxidant defence capacity and lipid profile in junior hurdlers. A pilot study. Biol. Sport 2014, 32, 161-168. [CrossRef]

39. Barbosa, P.O.; Pala, D.; Silva, C.T.; de Souza, M.O.; Amaral, J.F.D.; Vieira, R.A.L.; Folly, G.A.D.F.; Volp, A.C.P.; de Freitas, R.N. Açai (Euterpe oleracea Mart.) pulp dietary intake improves cellular antioxidant enzymes and biomarkers of serum in healthy women. Nutrition 2016, 32, 674-680. [CrossRef]

40. Cesar, L.T.; de Freitas Cabral, M.; Maia, G.A.; De Figueiredo, R.W.; De Miranda, M.R.A.; De Sousa, P.H.M.; Brasil, I.M.; Gomes, C.L. Effects of clarification on physicochemical characteristics, antioxidant capacity and quality attributes of açaí (Euterpe oleracea Mart.) juice. J. Food Sci. Technol. 2014, 51, 3293-3300. [CrossRef]

41. Agawa, S.; Sakakibara, H.; Iwata, R.; Shimoi, K.; Hergesheimer, A.; Kumazawa, S. Anthocyanins in Mesocarp/Epicarp and Endocarp of Fresh Acai (Euterpe oleracea Mart.) and their Antioxidant Activities and Bioavailability. Food Sci. Technol. Res. 2011, 17, 327-334. [CrossRef] 
42. Skemiene, K.; Pampuscenko, K.; Rekuviene, E.; Borutaite, V. Protective effects of anthocyanins against brain ischemic damage. J. Bioenerg. Biomembr. 2020, 52, 71-82. [CrossRef] [PubMed]

43. Badshah, H.; Kim, T.H.; Kim, M.O. Protective effects of Anthocyanins against Amyloid beta-induced neurotoxicity in vivo and in vitro. Neurochem. Int. 2015, 80, 51-59. [CrossRef] [PubMed]

44. Torma, P.D.C.M.R.; Brasil, A.V.S.; Carvalho, A.V.; Jablonski, A.; Rabelo, T.K.; Moreira, J.C.F.; Gelain, D.P.; Flôres, S.H.; Augusti, P.R.; Rios, A.D.O. Hydroethanolic extracts from different genotypes of açaí (Euterpe oleracea) presented antioxidant potential and protected human neuron-like cells (SH-SY5Y). Food Chem. 2017, 222, 94-104. [CrossRef] [PubMed]

45. Ereminas, G.; Majiene, D.; Sidlauskas, K.; Jakstas, V.; Ivanauskas, L.; Vaitiekaitis, G.; Liobikas, J. Neuroprotective properties of anthocyanidin glycosides against $\mathrm{H}_{2} \mathrm{O}_{2}$-induced glial cell death are modulated by their different stability and antioxidant activity in vitro. Biomed. Pharmacother. 2017, 94, 188-196. [CrossRef] 